\title{
Erratum to: A retrospective analysis of nonresponse to daily teriparatide treatment
}

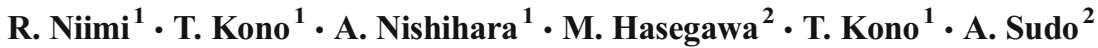

Published online: 17 May 2016

(C) International Osteoporosis Foundation and National Osteoporosis Foundation 2016

\section{Erratum to: Osteoporos Int}

\section{DOI 10.1007/s00198-016-3581-z}

The first sentence of the second paragraph in the section headed 'Changes in the bone turnover markers' concentrations in response to teriparatide treatment" should have read as follows: "In the nonresponders, the mean (SD) uNTX levels increased to $73 \mathrm{nmol} \mathrm{BCE} / \mathrm{mmol} \mathrm{Cr}(59)$ at 4 months, $87 \mathrm{nmol}$ $\mathrm{BCE} / \mathrm{mmol} \mathrm{Cr}$ (64) at 8 months, $84 \mathrm{nmol} \mathrm{BCE} / \mathrm{mmol} \mathrm{Cr}$ (53) at 12 months, $86 \mathrm{nmol} \mathrm{BCE} / \mathrm{mmol} \mathrm{Cr}$ (64) at 16 months, $80 \mathrm{nmol} \mathrm{BCE} / \mathrm{mmol} \mathrm{Cr}(74)$ at 20 months, and $77 \mathrm{nmol}$ $\mathrm{BCE} / \mathrm{mmol} \mathrm{Cr}(99)$ at 24 months (all $p<0.01$ vs. baseline; Wilcoxon signed-rank test) (Fig. 2b)".

In addition, both panels Fig. 1 contained errors. The amended figure is given here.

The authors apologise for any inconvenience caused.

The online version of the original article can be found at http://dx.doi.org/ 10.1007/s00198-016-3581-z.

R. Niimi

furikakefuri@hotmail.co.jp

1 Department of Orthopaedic Surgery, Tomidahama Hospital, 26-14, Tomidahamacho, Yokkaichi, Mie 510-8008, Japan

2 Department of Orthopaedic Surgery, Graduate School of Medicine, Mie University, Tsu, Japan 

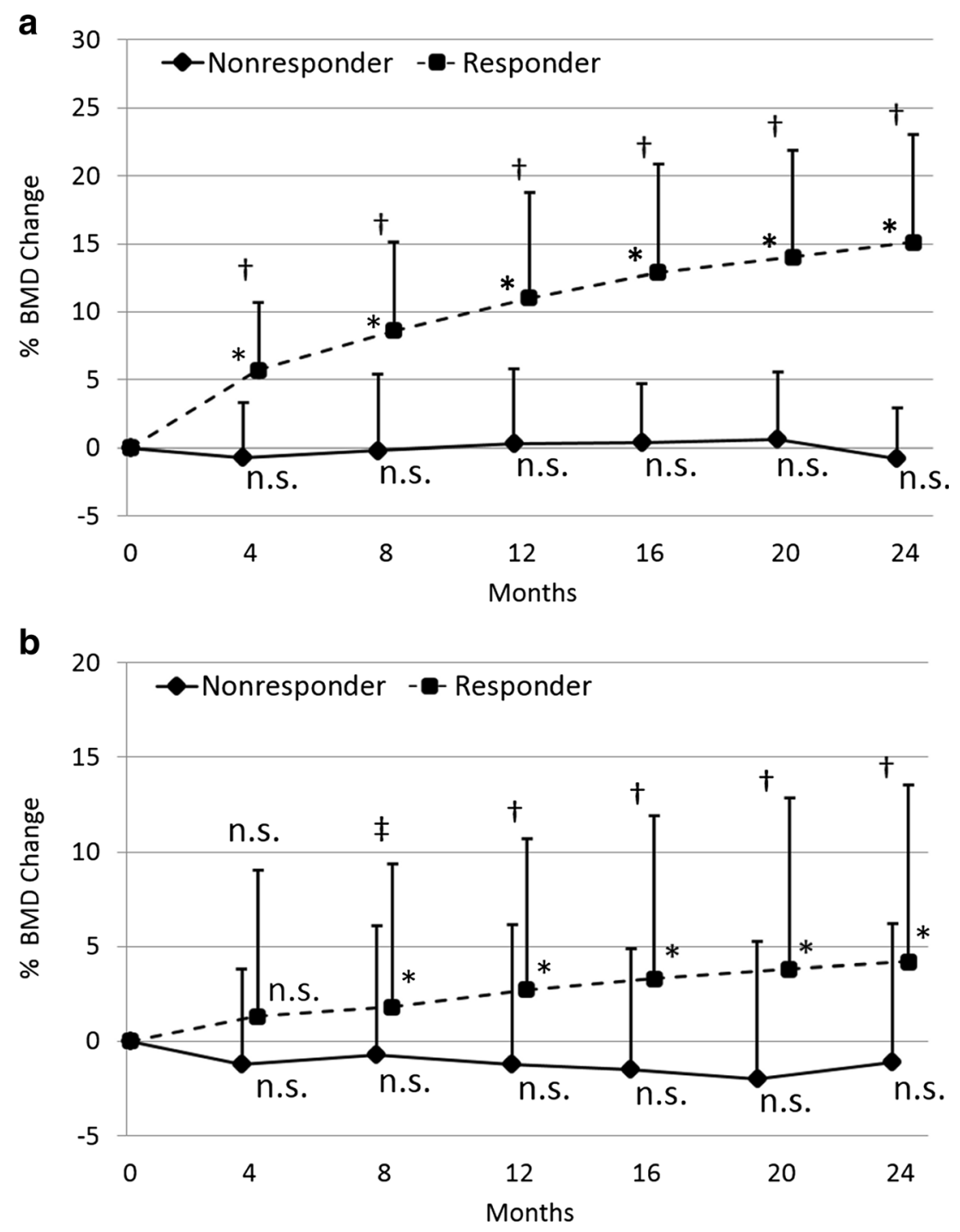